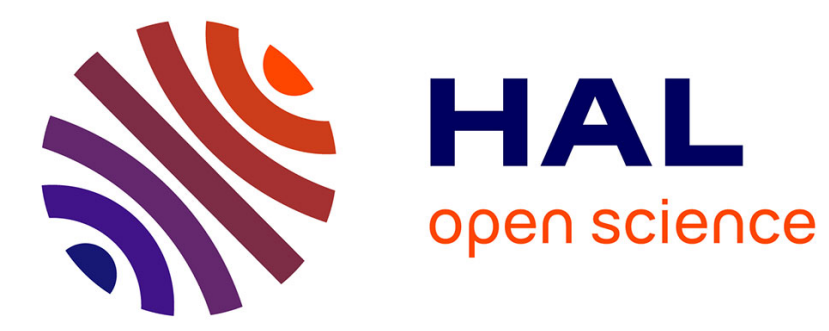

\title{
On the evolution of professional consulting
}

Thomas Gehrig, Werner Güth, René Levínský, Vera Popova

\section{To cite this version:}

Thomas Gehrig, Werner Güth, René Levínský, Vera Popova. On the evolution of professional consulting. Journal of Economic Behavior and Organization, 2010, 76 (1), pp.113. 10.1016/j.jebo.2010.02.016 . hal-00856607

\section{HAL Id: hal-00856607 https://hal.science/hal-00856607}

Submitted on 2 Sep 2013

HAL is a multi-disciplinary open access archive for the deposit and dissemination of scientific research documents, whether they are published or not. The documents may come from teaching and research institutions in France or abroad, or from public or private research centers.
L'archive ouverte pluridisciplinaire HAL, est destinée au dépôt et à la diffusion de documents scientifiques de niveau recherche, publiés ou non, émanant des établissements d'enseignement et de recherche français ou étrangers, des laboratoires publics ou privés. 


\section{Accepted Manuscript}

Title: On the evolution of professional consulting

Authors: Thomas Gehrig, Werner Güth, René Levínský, Vera Popova

PII:

S0167-2681(10)00122-8

DOI: doi:10.1016/j.jebo.2010.02.016

Reference: JEBO 2563

To appear in: Journal of Economic Behavior \& Organization

Received date: $\quad 25-8-2009$

Revised date: $\quad 27-1-2010$

Accepted date: $\quad$ 18-2-2010

Please cite this article as: Gehrig, T., Güth, W., Levínský, R., Popova, V., On the evolution of professional consulting, Journal of Economic Behavior and Organization (2010), doi:10.1016/j.jebo.2010.02.016

This is a PDF file of an unedited manuscript that has been accepted for publication. As a service to our customers we are providing this early version of the manuscript. The manuscript will undergo copyediting, typesetting, and review of the resulting proof before it is published in its final form. Please note that during the production process errors may be discovered which could affect the content, and all legal disclaimers that apply to the journal pertain. 


\title{
On the evolution of professional consulting*
}

\author{
Thomas Gehrig $^{\dagger} \quad$ Werner Güth ${ }^{\ddagger} \quad$ René Levínský $y^{\ddagger}$ \\ Vera Popova ${ }^{\ddagger}$
}

\begin{abstract}
In this experiment agents repeatedly invest in three state-specific assets. Theory requires portfolios to match the probabilities of the states. The treatments endow none, one, three, or all (of eight) investors with probability information. Will professional consulting evolve as an entrepreneurial activity? Will decisions follow theory or the $1 / n$-heuristic of equal investments in all assets? Will agents with probability information be asked and paid for advice? Portfolios designed with probability information reflect the benchmark but do not converge to it over time. Learning to avoid the $1 / n$-heuristic is extremely fast. Although advice is sought and readily paid for, recommendations are not always followed.
\end{abstract}

JEL Classification: G11, C73

Keywords: portfolio selection, expertise, advice, heuristics, experiments

${ }^{*}$ We gratefully acknowledge the comments by two anonymous referees leading to the major revision of this paper.

${ }^{\dagger}$ Institut zur Erforschung der wirtschaftlichen Entwicklung, Albert-Ludwigs-Universität, Kollegiengebäude II, Platz der Alten Synagoge, 79085 Freiburg im Breisgau, Germany.

${ }^{\ddagger}$ Max Planck Institute of Economics, Kahlaische Strasse 10, 07745 Jena, Germany.

${ }^{\S}$ Corresponding author. E-mail: popova@econ.mpg.de, Phone: +49-3641-686637, Fax: +493641-686667. 


\section{Introduction}

Entrepreneurship is sometimes glorified in the tradition of Schumpeterian innovators who manage to restructure markets and even whole industries. Innovators are pictured as individuals with vision, striking originality, and great talent. Very often, however, innovations result from a combination of competence and lucky circumstances. For instance, if one is able to paint and if, furthermore, others like one's paintings, one can obviously become a professional painter. In our study entrepreneurial activity is not inspired by a specific ability but by an informational advantage. Our entrepreneurs are informationally privileged and can therefore engage in professional consulting, provided, of course, there are clients willing to buy their services.

Although in reality it is difficult to tell who is informed and to what extent, here we abstract from such uncertainty. In our study it is commonly known that some agents are better informed than others. The better informed agents, however, do not sell their information but only advise on how to invest. Thus, there is also a grain of trust in the competence of the advisor when the client pays for costly advice and decides whether to follow it. Will professional consulting nevertheless evolve as an entrepreneurial activity and, if so, will clients follow the recommendations for which they have paid good money? We study the evolution of entrepreneurial behavior which does not require hiring employees. Instead, our prospective entrepreneurs are in possession of superior knowledge, allowing them to recommend a more adequate behavior to their clients.

Our market model and laboratory design (which, of course, have to abstract from the richness of the real world) implement a framework similar to Blume and Easley 
(1992). Investors expect three states of the world, each occurring with a certain probability. No one knows which state will actually occur. While some investors, called experts, know the objective probabilities of these states, nonexperts are unaware of these probabilities. All agents have to invest their capital repeatedly in the three state-specific assets. Only investments in the realized state generate a positive return, while all other investments are lost. The evolutionarily stable strategy (Blume and Easley, 1992) and strategic equilibrium is to invest proportionally to the probabilities of the states. This theoretical prediction coincides with probability matching (Vulkan, 2000). ${ }^{1}$

A nonexpert can either hope to be quick at learning or simply rely on heuristics to better adapt her behavior to market conditions. One heuristic is to invest evenly across $n$ asset categories. In the literature it is known as the $1 / n$ heuristic and is claimed to be "ecologically" rational, at least for some environments (Gigerenzer and Todd, 1999). For tasks like structuring of retirement fund investment, it is not, but it is nevertheless widely used (Benartzi and Thaler, 2001). If experts are available, one may ask them for advice. ${ }^{2}$ Our experiment provides a platform for professional consulting to evolve as an entrepreneurial activity. We are interested in the following questions: Will professional consulting evolve as an entrepreneurial activity? Or will experts exploit their informational advantage by keeping silent and increasing their gains from accurate portfolio choices rather than by benefiting from giving advice to others? Do the answers depend on the number of experts on the market? Will nonexperts follow advice or rather the $1 / n$ heuristic? Will experts behave optimally especially when doing so is rather easy since optimality coincides

\footnotetext{
${ }^{1}$ While probability matching is generally not optimal, it is optimal in our setup.

${ }^{2}$ Often, at least for the coarse sector, allocations of investment funds are available on the Internet. They typically deviate substantially from any heuristics.
} 
with probability matching?

Previous work on learning in recurrent allocation tasks has produced ambiguous results, depending on the complexity and difficulty of the underlying task. While Langholtz et al. (1993) and Ball et al. (1998) find fast convergence to equilibrium, non-convergence is observed when several local optima exist (e.g., Busemeyer et al., 1986; Rieskamp et al., 2003) or when the task is too difficult (Langholtz et al., 1994). Here we find that nonexperts initially use the $1 / n$-heuristic. ${ }^{3}$ However, participants learn surprisingly fast (within five rounds) to deviate from it. Experts choose portfolios closer to the evolutionarily stable ones from the very beginning. Further, we find experts selling their advice and nonexperts paying for, and relying on, it. The latter seems justified since experts, knowing the underlying probabilities, are likely to design better portfolios. Consulting activities take place more often when there is competitive pressure (i.e., more than one expert) because prices charged for expert services are lower. However, nonexperts seem to be skeptical and do not completely follow expert advice. They idiosyncratically deviate from expert recommendations so that their portfolios deviate more from the evolutionarily stable ones than those of experts.

One novelty of our work is the endogenous emergence of an important institution, namely that of professional consulting, illustrating for our special scenario that (and how) one can study entrepreneurship experimentally. Another novelty is that we explore investing with and without prior probability information together with decision making based on costly advice, which has previously been explored only separately. For instance, in studies of behavior in resource allocation tasks, similar

\footnotetext{
${ }^{3}$ Our study differs from the usual experimental studies on heuristics, typically run by psychologists, in that it is based on a formally defined scenario which is experimentally implemented by providing adequate monetary incentives and by inducing a clear-cut information asymmetry.
} 
to our investment task, costly advice has been excluded (e.g., Rieskamp et al., 2003; Langholtz et al., 1997). Research in psychology deals extensively with decision making in the presence of advice (a comprehensive review can be found in Bonaccio and Dalal, 2006) but, to the best of our knowledge, not in the context of investment tasks. Economists have recently examined whether advice facilitates social norms, cooperation, and coordination using different prominent game theoretic paradigms but never in the setting of a portfolio choice task (see, e.g., Schotter and Sopher, 2003, 2007; Chaudhuri et al., 2006).

The remainder of the paper is organized as follows. In section 2, we describe the basic scenario and the evolutionarily stable strategy which also qualifies as an equilibrium of the one-shot interaction. The experimental protocol and the hypotheses are specified in section 3. The results of the statistical analysis are reported in section 4. Section 5 concludes and suggests possible extensions.

\section{The model}

Let $N=\{1, \ldots, n\}$ denote the set of interacting agents in the stochastic environment with the (finite) set of possible states of nature denoted by $S=\{1, \ldots, s\}$. All agents are endowed with an equal amount of capital $K>0$. Agents $i \in M \subset N$ with $M=\{1, \ldots, m\}$ whom we call experts may advise agents $j \in N \backslash M=\{m+1, \ldots, n\}$ to whom we refer as nonexperts. It is commonly known that only experts have probability information, i.e., are aware of the vector $w=\left(w_{1}, \ldots, w_{s}\right)$ of the state probabilities $w_{k}$ with $w_{k}>0$ for all $k \in S$ and $w_{1}+\ldots+w_{s}=1$. When analyzing behavior, we are interested in the relative shares agents invest in the various assets, 
i.e., in the portfolio of investor $\ell \in N$.

$$
e_{\ell}=\left(e_{\ell 1}, \ldots, e_{\ell s}\right) \text { with } e_{\ell k} \geq 0 \text { for } k=1, \ldots, s \text { and } e_{\ell 1}+\ldots+e_{\ell s}=1 \text {. }
$$

We rely on the following course of events:

1. The probability vector $w=\left(w_{1}, \ldots, w_{s}\right)$ is exogenously given. Only experts $i \in M$ learn $w$, whereas nonexperts $j \in N \backslash M$ only know the number of possible states and that each of these states occurs with positive probability: $w_{k}>0$ for $k \in S$. All this is commonly known.

2. Nonexperts $j=m+1, \ldots, n$ can announce their willingness to pay $r_{j}^{i} \geq 0$ (hereafter WTP) for advice from some expert $i$. This means that nonexperts $j=m+1, \ldots, n$ are prepared to pay any price in the interval $R_{j}^{i}=\left[0, r_{j}^{i}\right]$. Nonexperts set $R_{j}^{i}=\emptyset$ if they do not wish to acquire advice.

3. All experts $i \in M$ express their wish to act as consultants by stating their fee $\phi_{i} \geq 0$. Whenever $r_{j}^{i} \geq \phi_{i}$ for some pairs $i, j$, expert $i$ has to recommend to nonexpert $j$ a portfolio composition

$$
\gamma_{i}^{j}=\left(\gamma_{i 1}^{j}, \ldots, \gamma_{i s}^{j}\right) \text { with } \gamma_{i k}^{j} \geq 0 \text { for } k=1, \ldots, s \text { and } \gamma_{i 1}^{j}+\ldots+\gamma_{i s}^{j}=1
$$

If $r_{j}^{i} \geq \phi_{i}$ and $r_{j^{\prime}}^{i} \geq \phi_{i}$ holds for two nonexperts $j$ and $j^{\prime}$, then expert $i$ must propose the same portfolios to both $j$ and $j^{\prime}$. Formally, $\gamma_{i}^{j}=\gamma_{i}^{j^{\prime}}=\gamma_{i}$. Moreover, experts have to follow their own recommendations. Similar to the ban on insider trading, this rule prevents professional experts from exploiting their customers. ${ }^{4}$

\footnotetext{
${ }^{4}$ We could have allowed for two types of professional consulting by enabling experts to sell both direct information about $w$ and/or investment advice. In the former case, we could (or could not) have required them to tell the truth, in the latter we could (or could not) have required them to
} 
If the WTP exceeds the required fee of several experts, i.e., $r_{j}^{i} \geq \phi_{i}$ holds for several $i$, then nonexpert $j$ has to choose one among all experts whose fees do not exceed her WTP. If the fees set by all experts are higher than the WTP of nonexpert $j$, then $j$ does not receive advice. An expert $i$ who does not want to be consulted chooses $\phi_{i}=+\infty$.

Denote the net transfers for information transmission by $\tau=\left(\tau_{1}, \ldots, \tau_{n}\right)$ with $\tau_{1}+\ldots+\tau_{n}=0$, where for experts $i$ the transfer $\tau_{i} \geq 0$ and for nonexperts $j$ the transfer $\tau_{j} \leq 0$.

4. All agents $\ell \in N$ invest specific capital $K_{\ell}=K+\tau_{\ell}$ between the assets. After possibly receiving advice in the form of proposals $\gamma_{i}^{j}$, nonexperts choose their portfolios $e_{j}$ freely, while experts are bound by their recommendations $e_{i}=\gamma_{i}$.

5. Finally, chance selects the actual state $k \in S$, and $k$ is publicly revealed.

The payoffs of all agents are determined by the two following rules:

- Only investments in the realized state pay.

- Payoffs are proportional to the investment in the actually realized state, and the total capital of all investors in a given round remains constant.

More specifically, the sum $n K$ of the initially equal wealth $K$ is redistributed, and the payoff of agent $\ell$ in the realized state $k$ is determined as

$$
\pi_{\ell k}=\frac{e_{\ell k} K_{\ell}}{\sum_{j=1}^{N} e_{j k} K_{j}} n K
$$

\footnotetext{
invest according to own advice. However, in such scenarios the set of strategies for the experts becomes huge and therefore difficult to analyze. For this reason, we implemented the simplest scenario.
} 
If this base game, consisting of stages 1 to 5 , is repeated infinitely often in rounds $t=1,2, \ldots$, which constant portfolio composition $e_{\ell}=\left(e_{\ell 1}, \ldots, e_{\ell s}\right)$ for $\ell \in N$ would be evolutionarily stable? Obviously, an infinite horizon implies that even relatively improbable states are going to occur. Hence, investing nothing in some state will definitely lead to losing all available resources. Consequently, an evolutionarily stable portfolio requires every player to invest in all states when the new endowments $K_{\ell}$ in round $t+1$ are the gains $\pi_{\ell k}$ in round $t$ for all investors $\ell$. Actually, Blume and Easley (1992), who focus on the special case $M=\emptyset$, have shown that the only evolutionarily stable portfolio composition corresponds to the probability vector $w$, i.e.,

$$
e^{*}=\left(e_{1}^{*}, \ldots, e_{s}^{*}\right)=w=\left(w_{1}, \ldots, w_{s}\right) .
$$

Note that an evolutionary approach relies on Darwinian selection and requires no cognition at all on the part of the players, especially no awareness of $w$ (see AlósFerrer and Ania, 2005, for a more general analysis).

We are also interested in what myopic optimization by all players will predict and whether professional expertise will evolve. Both require reasoning on the part of the players. As a next step, we therefore show that (2) is not only an evolutionarily stable strategy but also a Nash equilibrium (Nash, 1951) of the one-shot interaction, i.e., of the base game. If all agents in our setup deliberately strive to maximize their payoff function (1), then $e^{*}=w$ is the game theoretic equilibrium of the one-shot interaction.

Proposition 1 Investing proportionally to probabilities of states according to

$$
e_{\ell}=e^{*}=w \text { for all } \ell=1, \ldots, N
$$

constitutes the unique interior equilibrium of the base game. 
Proof: See appendix.

What if one wants to play safe by investing the same amount in all states? If all investors do so, each investor $\ell$ will receive the same share of the unit supply of each asset $k$. Thus, regardless of the state chosen, investor $\ell \in N$ gets back $K_{\ell}$. In our view, the unbiased portfolio composition

$$
e^{+}=\frac{1}{S}(1, \ldots, 1)
$$

for all $\ell \in N$ leading to symmetric portfolios is a likely focal point, at least for nonexperts who have not sought advice (hereafter naive nonexperts). We refer to relying on $e^{+}$as the $1 / n$-heuristic ${ }^{5}$ (Gigerenzer and Todd, 1999).

\section{Experimental protocol}

Before the main sessions, we ran a pilot experiment in the videolab of the Max Planck Institute of Economics in Jena to see how easily participants understood the instructions and how challenging they considered their decision tasks. ${ }^{6}$ The computerized experiment, using z-Tree (Fischbacher, 2007), was conducted in March and April 2007 in the experimental laboratory of the same institute. The participants were undergraduate students from the University of Jena, mainly of economics,

\footnotetext{
${ }^{5}$ Given our notation, the " $1 / s "$ heuristic would be a more appropriate name. However, we prefer to stick to the name common in the literature.

${ }^{6}$ We invited 16 subjects, devided them randomly into pairs and placed each pair in one of eight isolated, soundproof cabins. Instructions, procedures, and software were the same like in the main experiment, except for the following. Both subjects were required to discuss and agree on a common decision for their pair. We video recorded all the discussions. Each subject was paid the amount earned by her pair.
} 
business administration, and the sciences. To invite them we used the online recruitment system for economic experiments ORSEE (Greiner, 2004). We conducted eight sessions, each starting with reading the instructions, running four practice rounds, and answering a control questionnaire to assure that the instructions were fully understood. In each session, only the 24 subjects with the highest score on the questionnaire were selected for participation. Eventually, 192 students took part in the experiment. ${ }^{7}$ The sessions lasted about 90 minutes. Subjects earned 15 euros on average (we did not pay a show-up fee), the exchange rate being 300 experimental currency units for 1 euro. $^{8}$

Each treatment consisted of three phases of 15 rounds, i.e., 45 rounds in total. In each round, subjects received an endowment, which they were supposed to invest in three different states of nature, each occurring with a given positive probability. After the investment decisions were made, with or without knowing $w$ and with or without advice, subjects were informed about which state occurred and their resulting profits. The profits (see equation (1)) were calculated for each matching group of eight subjects.

In each treatment, there were six matching groups with eight subjects each. The four treatments differed in the number of experts per group. In treatment $\mathrm{T} 0+8$, the number of experts per matching group was zero, in $\mathrm{T} 1+7$ one, in $\mathrm{T} 3+5$ three, and in T $8+0$ eight. Subjects were randomly assigned to a group and (in T $1+7$ and $\mathrm{T} 3+5)$ to a role (of expert or nonexpert). Groups and individual roles remained constant throughout the 45 rounds.

Of course, the $\mathrm{T} 3+5$ and $\mathrm{T} 1+7$ markets did not only differ in the number of

\footnotetext{
${ }^{7}$ The 31 students who did not qualify for the experiment received a compensation of 5 euros.

${ }^{8}$ An English translation of the instructions can be found in Gehrig et al. (2008).
} 
experts but also in the number of possible clients (i.e. nonexperts interested in buying advice). However, inducing the same number of potential clients would have changed the market size and thereby market clearing. Therefore we maintained the same market size (of eight investors) across treatments.

During the experiment, three different probability vectors $w$ were applied, each of them lasting for 15 rounds. More specifically, probabilities were exogenously given in rounds 1, 16, and 31. All subjects were reminded that the probabilities had changed. The vectors were the following:

- in phase 1: $w=(0.25,0.25,0.5)$

- in phase $2: w=(0.4,0.2,0.4)$

- in phase 3: $w=(0.15,0.3,0.55)$

To keep the experiment comparable across treatments, matching groups with the same label (e.g., "two") received the same sequence of randomly chosen states in rounds $1,2, \ldots, 45$, independent of the treatment. Applying the same random realizations across treatments meant that treatments differed only in the number of experts. Thus, shifts in behavior across treatments will be interpreted as $m$-effects, i.e., resulting from changes in the number $m$ of experts. The six groups for each treatment faced the same probability distribution but different random sequences of selected states. ${ }^{9}$

In $\mathrm{T} 1+7$ and $\mathrm{T} 3+5$, nonexperts were allowed to offer rewards to experts in exchange

\footnotetext{
${ }^{9}$ If one matching group observes nonrepresentative realizations, this will not affect other matching groups. Thus, most nonexperts have a realistic chance to infer the true probabilities by observing the random realizations.
} 
for advice on how to invest. The experts, in turn, could choose their fees. Whenever a reward offered exceeded the fee, the expert became an advisor to the nonexpert (nonexperts receiving advice will be called clients hereafter), who had to pay the required fee. In $\mathrm{T} 3+5$, it was possible for one reward to be higher than the fees of two or three experts. In this case, the nonexpert was required to select only one advisor $^{10}$, whereas experts could give advice to more than one nonexpert. Experts could not reveal their private information about $w$, the probabilities of the states, but only recommend a portfolio composition which they were obliged to use themselves.

Why do experts not simply communicate the probabilities of the states? In real life, clients seeking expert advice do not have access to all the information available to their advisors. Moreover, recommendations are not based simply on information - it is the advisor who produces the recommendation by utilizing her experience based on the information she has. Last, to assume that advice is a homogeneous product is extremely unrealistic. These are the features we wanted to capture by not allowing experts to simply reveal the probabilities of the states. It is true that our experts (since randomly assigned to that role) did not have more experience than nonexperts. By requiring them to communicate their own portfolio allocation as a recommendation, we made sure that clients received advice which their advisors considered the best possible one.

Based on our benchmark analysis, we wanted to test the following hypotheses:

$H_{1}$. Investment will depend on the role of the agent.

\footnotetext{
${ }^{10}$ Although it was possible for a nonexpert to identify an advisor from one phase to the next, we do not have any reason to believe that reputation effects play a role. Whenever nonexperts had a choice among advisors, nonexperts almost always selected the cheapest one.
} 
a. Investment in treatments with more experts will be closer to $w$.

b. Experts will invest closer to $w$, followed by clients and naive nonexperts.

c. Initially in each phase, mainly the naive nonexperts will invest according to the $1 / n$-heuristic; later, portfolios will gradually develop away from the $1 / n$ heuristic and converge to $w$.

$H_{2}$. Professional consulting will evolve.

a. Nonexperts will be willing to pay for advice.

b. Experts will require positive fees for their services.

c. Clients will follow recommendations.

$H_{3}$. Competition among experts will lower the average fees and thereby induce more advice and faster convergence to $w$.

$H_{4}$. Agents investing closer to $w$ will earn more.

\section{Results}

\subsection{Does investment follow $w$ or $1 / n$ ?}

Table 1 summarizes mean, median, and standard deviation of investment by treatment and phase. Clearly, the median investment in T $8+0$ and $\mathrm{T} 3+5$ corresponds 
to $w$. In contrast, the median investment in $\mathrm{T} 0+8$ resembles $1 / n$. In $\mathrm{T} 1+7$ investment depends on the phase - in phase 2 , it is consistent with $w$, whereas in phases 1 and 3 it better matches $1 / n$. The latter finding can be explained by fewer nonexperts in $\mathrm{T} 1+7$, who received advice in phases 1 and $3 .^{11}$ Thus, in markets with more experts (like in T $3+5$ and $\mathrm{T} 8+0$ ) portfolio choices on average are more accurate. Furthermore, there is a first hint that nonexperts follow advice.

\section{TABLE 1}

Checking for equality between actual investment and the game theoretic benchmark versus actual investment and $1 / n$ statistically yields a rather consistent picture in the two treatments with more informed agents (Table 2). In most cases, equality between actual investment and $w$ cannot be rejected, while equality between actual investment and $1 / n$ is frequently rejected (Wilcoxon-Mann-Whitney rank-sum test $^{12}$ ). For example, in $\mathrm{T} 8+0$ equality between investment and $w$ can be rejected only in 1 of 9 cases. In contrast, equality between investment and $1 / n$ can be rejected in all cases. In $\mathrm{T} 1+7$ equality between investment and $w$ is rejected less often than equality between investment and $1 / n$. For treatment $\mathrm{T} 0+8$ the results reverse - equality between investment and $w$ is rejected more often (6 of 9 cases) than equality between investment and $1 / n$ (3 of 9 cases).

\footnotetext{
${ }^{11}$ Due to the high fees for advice on the monopoly market for expertise, a much smaller fraction of nonexperts receives a recommendation in $\mathrm{T} 1+7$ as compared to $\mathrm{T} 3+5$, especially in phases 1 and 3 (see Table 5).

${ }^{12}$ Unless specified differently, the tests are always two-sided and based on six independent observations, one for each market of eight investors. We report the comparison of means only. Results do not change when medians are considered.
} 
Interestingly, the results in Table 2 show that investment in $\mathrm{T} 3+5$ is even closer to $w$ than investment in $\mathrm{T} 8+0$ in spite of the larger number of experts in $\mathrm{T} 8+0$. Although surprising at first, this finding coincides with the results by Iyengar and Schotter (2008). According to them, the need for advisors to produce recommendations and the availability of recommendations for clients facilitates learning for both advisors and clients, compared to decision makers facing the same decision task without advice. ${ }^{13}$ Why does the process of providing and receiving advice induce more thorough deliberation and better insights than making decisions in isolation? It seems that the additional responsibility and accountability of advisors induce them to think more carefully about their recommendation. ${ }^{14}$ Clients, on the other hand, can compare their own idea with that of a more informed investor, possibly rendering the former more reflective and thoughtful. Such arguments may explain why experts and their clients invest closer to $w$ than experts who do not give advice, as in $\mathrm{T} 8+0 .{ }^{15}$

\section{TABLE 2}

Regularity 1 : Portfolios on the market with competition among experts are closest to $w$.

\footnotetext{
${ }^{13}$ Advisors in this study were neither trained nor did they have access to more information compared to their clients.

${ }^{14}$ One of the findings of Iyengar and Schotter (2008) is that advisors whose advice cannot be neglected learn faster than advisors whose advice can be ignored.

${ }^{15}$ Just presenting the number of correct portfolios by treatment and phase would neglect too many choices deviating only marginally from $w$ : in phase 1 (where $w=(25,25,50)$ ) a portfolio composition $(23,23,54)$ would, e.g., not be counted as correct, although it is close to $w$. The share of correct decisions in the sense of $e=w$ is $24 \%$ in $\mathrm{T} 8+0$ and $2 \%$ in T $0+8$. In T $3+5(\mathrm{~T} 1+7)$ it is $17 \%(14 \%)$ for experts, $8 \%(8 \%)$ for clients, and $0 \%(2 \%)$ for naive nonexperts.
} 


\subsection{Does investment converge to $w$ or to $1 / n$ ?}

To check for learning effects over time, we run eight separate Tobit regressions ${ }^{16}$, one for each treatment and benchmark. The dependent variables are the Euclidian distance between actual investment and the heuristic $1 / n$ (Table 3) and the Euclidian distance between actual investment and $w$ (Table 4). To account for the fact that every subject makes decisions repeatedly within a fixed group, we add an individual-specific random effect and a group-specific fixed effect. ${ }^{17}$ Whenever possible we differentiate between experts, clients, and naive nonexperts by introducing dummies for each role as dependent variables in the regressions. Since the probability distribution of the states changes from one phase to the next, we account for learning within each phase by interacting a dummy for each phase with "round", the latter going from 1 to 45 .

Consider first Table 3. Subjects in T $0+8$ start off much closer to $1 / n$ than subjects in $\mathrm{T} 8+0$ (see the magnitude of the significant constant for $\mathrm{T} 8+0$ ). The positive and significant time variables indicate that within the same phase the distance to the $1 / n$ heuristic increases over time for most phases and treatments. Also, the distance to the $1 / n$ is significantly larger for experts and clients than for naive nonexperts, suggesting once again that clients follow recommendations. ${ }^{18}$

\footnotetext{
${ }^{16}$ The choice of a Tobit model is appropriate since our dependent variable is left censored.

${ }^{17}$ Tobit models with individual random effects and group fixed effects yield consistent estimates if the number of observations per group is large enough (Cameron and Trivedi, 2005). In our case this condition is met: 8 individuals $* 45$ decisions $=360$ observations per group.

${ }^{18}$ To check whether the estimated coefficients for the variables Expert, Client, and Naive are significantly different from each other, we conducted pairwise Wald tests. The Null Hypothesis states that there is no difference between the coefficients. In $\mathrm{T} 1+7$ Expert does not differ from Client $(p=0.9651)$ but differs from Naive $(p=0.0299)$. Client differs from Naive $(p=0.0000)$.
} 
Nonexperts in $\mathrm{T} 0+8$ start off very close to $1 / n$ (e.g., Euclidian distance $=10$ for phase 1 in Fig. 2 in the appendix) but quickly reach the initial value of the Euclidian distance of experts ( $=25$ for phase 1$)$ in $\mathrm{T} 8+0$ after only 5 rounds (in most phases). Given that the task at hand is not trivial, especially in treatment $\mathrm{T} 0+8$, where the probabilities of the states can be inferred only from previous realizations of the states and where therefore relying on heuristics makes sense, it is surprising how fast subjects deviate from using heuristics.

\section{TABLE 3}

Regularity 2 : Some subjects, mostly naive nonexperts, initially rely on the $1 / n$ heuristic but then try to develop a more sophisticated investment strategy.

Although investment moves away from $1 / n$, it does not always come close to $w$. The time variables from the regressions in Table 4 are again positive and significant, indicating divergence from $w$ over time. This contradicts the last part of $H_{1} c$, predicting an evolution toward $w$ when the phase ends. Given that probability matching seems so natural, it is intriguing to notice that there is no convergence to the benchmark (see Fig. 3 in the appendix). Nevertheless, not only experts but also clients invest closer to $w$ (see the significant coefficients for Expert, Client, and Naive) than naive nonexperts, with the distance to $w$ for experts being smaller than for clients (in $\mathrm{T} 1+7$ ) and the one for clients being smaller than for naive nonexperts (for both $\mathrm{T} 1+7$ and $\mathrm{T} 3+5) .{ }^{19}$ An illustration of the regressioins in Tables 3 and 4 can be found in the appendix (Fig. 2 and Fig. 3).

In T 3+5 Client does not differ from Expert $(p=0.1866)$, Expert differs from Naive $(p=0.0227)$, and Client differs from Naive $(p=0.004)$.

${ }^{19}$ Again, in order to tell whether the estimates for Expert, Client, and Naive are significantly different from each other, we compared them pairwise using a Wald test, with the Null Hypothesis 


\section{TABLE 4}

Regularity 3 : Experts invest closer to $w$ than clients, who in turn invest closer to $w$ than naive nonexperts. However, learning ${ }^{20}$ does not imply convergence to $w$.

The qualitative analysis of the pilot session conducted in the video lab of the Max Planck Institute of Economics in Jena suggests one reason why investment does not converge to $w$ : in spite of the random procedure according to which one of the states is selected in each round (of course depending on $w$, but on nothing else), not only naive nonexperts but also clients and experts pay much attention to the past realizations of states when investing. Quantitatively, we were able to confirm that subjects tend to reduce their investment in the state that was previously realized, a phenomenon known as gambler's fallacy (for details on the econometric procedure and the regression results, see Gehrig et al., 2008).

\subsection{Does professional expertise evolve?}

Nonexperts readily seek advice (see Table 5 ). In treatments $\mathrm{T} 3+5$ and $\mathrm{T} 1+7$, on average more than $90 \%$ of all nonexperts are prepared to pay for advice. ${ }^{21}$ Experts on the supply side demonstrate a lively interest in becoming consultants - about $80 \%$ in both treatments are willing to give advice. The shares of agents asking for,

claiming that coefficients are the same. In T $1+7$ Expert differs from Client $(p=0.0133)$ and Naive $(p=0.0005)$. Client differs from Naive $(p=0.0012)$. In T $3+5$ Expert does not differ from Client $(p=0.5467)$; Expert differs from Naive $(p=0.0027)$, and so does Client $(p=0.0000)$.

${ }^{20}$ Since all investors in a group receive the same feedback, the different behavior of experts, clients, and naive nonexperts questions that behavior is shaped by reinforcement learning.

${ }^{21}$ Only nonexperts willing to pay a sum greater than zero are considered. 
and offering, advice in both treatments are very similar. The frequency of actual consulting, however, differs considerably. In $\mathrm{T} 1+7$ one third of the agents who request advice also receive it. In $\mathrm{T} 3+5$ about two thirds obtain recommendations. Only $51 \%$ of the experts in $\mathrm{T} 3+5$ are actually hired, compared to $87 \%$ in $\mathrm{T} 1+7$ due to competition on the supply side in $\mathrm{T} 3+5$. In both treatments all experts require a fee greater than zero for their services. ${ }^{22}$

It is not trivial that experts are willing to offer advice. Remember that the specific profit function creates an incentive to not reveal their private information about the probabilities of the states: the more an agent invests in the state that will occur and the less others invest, the higher the agent's profits! Since advisors have to invest the same portfolio they recommend, they cannot exploit both the advantage from better information and the benefit from consulting. It is far from obvious whether and when the informational advantage can be compensated by earnings from consulting. This may depend on the consulting fees, the number of clients, and, most importantly, on the number of potential advisors on the market. Since every expert can serve many clients, the informational advantage of experts who decide against consulting diminishes when other experts engage in consulting. Indeed, we do not see any difference in the earnings of advisors compared to nonadvisors.

\section{TABLE 5}

Regularity 4 : In case of asymmetric information, professional expertise in the sense of experts offering costly advice and nonexperts willing to pay for it, is a robust phenomenon. Especially when experts compete in offering their services and

\footnotetext{
${ }^{22}$ Among the nonexperts, only one subject per treatment stated a zero willingness to pay, and this only in one of the three phases.
} 
therefore reduce their fees professional consulting is twice as likely than in the case of only one expert.

Do nonexperts follow recommendations being aware that experts cannot cheat? Indeed, the evidence from Tables 3 and 4 above indicates that advice is followed. Tables 6 and 7 verify this claim once again. Table 6 lists descriptive statistics on mean and median investment of clients as well as the recommendation they receive. The Wilcoxon rank-sum test cannot reject the equality between these two variables in most of the cases (Table 7). ${ }^{23}$ Still, the Euclidian distance between advice and investment by clients is not zero (Fig. 4 in the appendix); it even significantly increases over time for all phases in $\mathrm{T} 3+5$, while it does not change in $\mathrm{T} 1+7$. Apparently, the influence of advisors diminishes over time in $\mathrm{T} 3+5$. Do clients learn to play the game better by themselves and therefore abandon advice? Our regression results, as well as fig. 2 and fig. 3 show that this is not the case - client's investment diverges from $w$ over time (as well as from $1 / n$ ). For $\mathrm{T} 1+7$ the Euclidian distance from both $w$ and $1 / n$ does not change. ${ }^{24}$ So, advice is followed closely but not blindly. ${ }^{25}$

\section{TABLE 6, TABLE 7}

Why do clients not just imitate the behavior of advisors? In economics, the effect of

\footnotetext{
${ }^{23}$ We are aware of the fact that two independent observations in phase 3 of $\mathrm{T} 1+7$ are not enough to ensure the reliability of the test. Nevertheless, we list the results for the sake of completeness.

${ }^{24}$ These results are based on Tobit regressions performed separately for each treatment. The dependent variable is the Euclidian distance between actual investment by clients and each advice, $w$, and $1 / n$. The independent variables are interactions between a phase dummy for each phase and round (like on tables 3 and 4), and a constant. Individual-specific random effects and group-specific fixed effects account for the repeated responses within fixed groups.

${ }^{25}$ The share of decisions that followed advice exactly is $24 \%$ in $\mathrm{T} 1+7$ and $13 \%$ in $\mathrm{T} 3+5$.
} 
advice on behavior in different games has been studied by Schotter (2003), Schotter and Sopher (2003, 2006, 2007), Chaudhuri et al. (2006), and Kuang et al. (2007). All these studies find that advice is followed and that it shapes behavior.

In psychology, the research on this topic is more detailed and also more controversial. The literature on Judge-Advisor Systems (see, e.g., the review by Bonaccio and Dalal, 2006) provides insights on when, why, and to which extent advice is implemented. For example, clients are more likely to follow advice when they are less knowledgeable than their advisor (e.g., Harvey and Fischer, 1997), when advice is solicited rather than provided without request (Gibbons et al., 2003), when tasks are complex (Schrah et al., 2006), when advice is accurate, and when the goals of clients and advisors are aligned (Schotter, 2003).

In our setup, implementing advice is facilitated by rendering experts more knowledgeable than nonexperts, by challenging nonexperts with a nontrivial task, by aligning the interests of advisors and advised (experts are required to invest according to their recommendation), and by nonexperts freely deciding whether to purchase advice. Why do nonexperts not simply implement the advice? According to the literature on Judge-Advisor Systems, one well-established reason is "egocentric advice discounting" (e.g., Yaniv, 2004b; Yaniv and Kleinberger, 2000). Decision makers often do not follow advice as closely as they should to truly benefit from it. Thereby they discount the opinion of the advisor too strongly, when combining it with their own. This behavior is believed to be due to the client's impossibility to grasp the advisor's internal justification for the recommendation. In contrast, clients are fully aware of their own arguments, rendering their own opinion less ambiguous than the recommendation (Yaniv and Kleinberger, 2000; Yaniv, 2004a,b). Other reasons for discounting advice may be an anchoring and adjustment strategy (Tversky and Kahnemann, 1974), with the own initial opinion being the anchor that 
is gradually but insufficiently adjusted toward the advisor's recommendation (e.g., Harvey and Fischer, 1997), an egocentric bias (Krueger, 2003), and conservatism (Harvey and Harries, 2004).

Regularity 5 : Although clients do not implement recommendations blindly, they are strongly influenced by them.

\subsection{Is there any impact of competition?}

\section{FIGURE 1}

Fig. 1 illustrates the average fees required by advisors, the average willingness to pay for advice, and the average fees finally paid for advice. All three variables in $\mathrm{T} 1+7$ frequently lie above those in $\mathrm{T} 3+5$. In the following we will focus on the WTP and the fees that were actually paid. Fees in T $1+7$ are significantly higher than those in T $3+5$ in phases 1 (61 ECU vs. 26 ECU) and 2 (64 ECU vs. 23 ECU) (Wilcoxon rank-sum test, $p=0.0264$ and $p=0.0088$, respectively). ${ }^{26}$ Over time, fees increase nonsignificantly when there is an expert monopoly (Wilcoxon signed rank test, phase 1 (61 ECU) versus phase 2 (64 ECU), $p=0.16$ ). Fees decrease when experts compete (nonsignificantly between phases 1 (26 ECU) and 2 (23 ECU) and significantly between phases 2 (23 ECU) and 3 (18 ECU), Wilcoxon signed rank test, $p=0.5$ and $p=0.08$, respectively). WTP does not differ significantly across treatments (Wilcoxon rank-sum test, $p=0.34, p=0.26, p=0.75$, for phases 1 , 2 , and 3 , respectively). WTP does not change over time in $\mathrm{T} 3+5$. In contrast, in

\footnotetext{
${ }^{26}$ For phase 3 the fees in $\mathrm{T} 1+7$ are so high that advice is provided in only two out of six groups. Thus, there are not enough independent observations for a reliable test.
} 
T 1+7 WTP significantly increases from phase 1 to phase 2 (Wilcoxon signed rank test, $p=0.0277$ ); WTP does not change from phase 2 to phase 3 .

Regularity 6 : Fees are higher on the monopolistic market for advice. Competition lowers fees over time.

Nonexperts apparently gain from competition among experts by lower fees, whereas experts, both as a group and individually, suffer from competition: the total amount collected by advisors is 2,280 ECU in T $1+7$ versus only 1,250 ECU in $\mathrm{T} 3+5$. Whether two experts are enough for competition is a possibility that we did not explore.

\subsection{Profits}

Does it pay to invest according to $w$ ? Table $8^{27}$ shows that in all treatments earnings are higher the closer investment is to $w$. In $\mathrm{T} 1+7$, profts also improve with a growing distance to $1 / n$, questioning the "ecological rationality" of the $1 / n$-heuristic (Gigerenzer and Todd, 1999).

\section{TABLE 8}

Regularity 7 : Investing close to $w$ pays.

\footnotetext{
${ }^{27}$ Again we ran Tobit regressions with individual-specific random effects and group-specific fixed effects. We use the Tobit model because the dependent variable (profit) is left-censored, since we do not allow for negative profits.
} 


\section{Conclusion}

With field data it is rather difficult, if not impossible, to compare financial markets with and without investment advisors. Here we have concentrated on the evolution of consulting as an entrepreneurial activity in a rather specific market scenario, the advantages being that there is an intuitive and focal game theoretic benchmark $\left(e^{*}=w\right)$ as well as a simple heuristic $1 / n$. Furthermore, we have been able to study the effect of competition on the market for financial advice.

In our setting we find that professional consulting evolves easily: advisors readily offer their services against payment and clients willingly purchase advice rather than relying on the $1 / n$ heuristic and learning only from feedback information. Our study shows how one can experimentally study the evolution of professional consulting and thus, more generally, of entrepreneurship. Another finding may be interesting for behavioral mechanism design: the best performing markets (in terms of proximity to the game theoretic benchmark) are not the ones on which all agents are informed but the ones with asymmetric information and competition among the better informed agents.

Future research could try to add more realism to the experimental design, e.g., by introducing advisors who do not have to follow their own recommendations. Crawford and Sobel (1982), for example, have inspired a whole research area on the incentives of experts to manipulate information. ${ }^{28}$ In our experiment manipulation of advice was explicitly ruled out. Under conditions where advice can be manipulated, we expect that the evolution of consulting might be impaired. On the other hand,

\footnotetext{
${ }^{28}$ See Farrell and Rabin (1996), Sobel (2007), and Krishna and Morgan (2008) for recent surveys of this literature.
} 
allowing for the reputation of experts might help to restore consulting activity.

An interesting question that we have not tried to answer yet is why nonexperts sometimes buy expert advice but then do not follow it. Future research may focus on identifying how clients deviate from the recommendation they received and explore possible reasons for this behavior (e.g., doubt in the competence of experts, etc.). In our view, one should not jump to conclusions but try to address such questions in the light of more data, especially concerning this and related scenarios allowing for the evolution of professional consulting.

While in our setup every 15 rounds a new endowment of funds is distributed among subjects, a scenario could be implemented more closely to that in Blume and Easley (1992), in which subjects are endowed only once in the first round. This would punish experimentation more heavily by marginalizing unlucky experimenters and support more defensive actions. Whether such a scenario would be more favorable for the evolution of professional consulting, can only be answered by future research. 


\section{Tables}

Table 1: Descriptive statistics on investment behavior across treatments.

Table 2: Wilcoxon rank-sum test $p$ values for equality between actual investment and $w$ and actual investment and $1 / n$.

Table 3: Tobit random effects regressions explaining the Euclidian distance $E D^{1 / n}$ between investment and the heuristic $1 / \mathrm{n}$ by treatment.

Table 4: Tobit random effects regressions explaining the Euclidian distance $E D^{w}$ between investment and $w$ by treatment.

Table 5: Supply and demand on the market for professional expertise.

Table 6: Mean, median, and standard deviation of investment of clients as well as advice they receive by treatment, phase, and state.

Table 7: Wilcoxon rank-sum test $p$ values for equality between average investment of clients and average recommendations by treatment, phase, and state.

Table 8: Tobit random effects regression explaining profits by treatment.

\section{$7 \quad$ Figures}

\subsection{Figures placed in the main text}

Figure 1: Mean required fees, mean willingness to pay, and mean paid fees in $\mathrm{T}$ $1+7$ and $\mathrm{T} 3+5$. 


\subsection{Figures placed in the appendix}

Figure 2: Euclidian distance from the $1 / n$ portfolio by treatment over time.

Figure 3: Euclidian distance from the w-portfolio by treatment over time.

Figure 4: Euclidian distance from the recommended portfolio by treatment over time. 
Table 1: Descriptives: investment across treatments

\begin{tabular}{lllllllllll}
\hline \multirow{2}{*}{$\begin{array}{c}\text { Treat- } \\
\text { ment }\end{array}$} & Pha- & \multicolumn{4}{c}{ Mean } & \multicolumn{4}{c}{ Median } & \multicolumn{3}{c}{ SD } \\
\cline { 2 - 10 } & se & B & C & A & B & C & A & B & C \\
\hline $8+0$ & 1 & 27.8 & 26.6 & 45.6 & 25 & 25 & 50 & 12.7 & 12.9 & 20.8 \\
& 2 & 39.2 & 22.4 & 38.4 & 40 & 20 & 40 & 12.4 & 19 & 12.2 \\
& 3 & 18.2 & 29.6 & 52.2 & 15 & 30 & 55 & 14.3 & 11.9 & 18.3 \\
\hline \multirow{2}{*}{$3+5$} & 1 & 25.2 & 26.7 & 48 & 25 & 25 & 50 & 16.9 & 18.4 & 25.8 \\
& 2 & 39.8 & 21.1 & 39 & 40 & 20 & 40 & 17.6 & 17.7 & 17.6 \\
& 3 & 18.9 & 28.8 & 52.3 & 15 & 30 & 55 & 17.7 & 14.1 & 23.1 \\
\hline \multirow{2}{*}{$1+7$} & 1 & 29.5 & 29.1 & 41.3 & 30 & 30 & 40 & 17.3 & 19.4 & 22.3 \\
& 2 & 39.1 & 23 & 37.8 & 40 & 20 & 35 & 19.1 & 17.9 & 20.1 \\
& 3 & 25.2 & 30.6 & 44.2 & 30 & 33 & 40 & 18.4 & 14.8 & 21.9 \\
\hline $0+8$ & 1 & 30.6 & 35.4 & 34 & 32 & 33 & 34 & 19.9 & 20.2 & 20.3 \\
& 2 & 36.7 & 30 & 33.2 & 33 & 30 & 34 & 17.6 & 17.1 & 16.9 \\
& 3 & 26.9 & 30.2 & 42.9 & 30 & 33 & 40 & 17.8 & 16.6 & 22.7 \\
\hline
\end{tabular}

Data is organized by treatment, phase, and state; benchmark:

$w_{1}=(25,25,50), w_{2}=(40,20,40), w_{3}=(15,30,55), 1 / n$ heuristic $=(100 / 3,100 / 3,100 / 3) ;$ states are denoted by A, B, C 
Table 2: Wilcoxon rank-sum test p-values for equality between investment and $w$ and investment and $1 / n$

\begin{tabular}{cccccccc}
\hline \multirow{2}{*}{ Treat- } & Pha- & \multicolumn{3}{c}{$p$ for equality to $w$} & \multicolumn{3}{c}{$p$ for equality to $1 / n$} \\
\cline { 3 - 8 } ment & se & A & B & C & A & B & C \\
\hline $8+0$ & 1 & 0.31 & 0.31 & 0.05 & 0.002 & 0.002 & 0.002 \\
& 2 & 0.31 & 1 & 0.31 & 0.002 & 0.002 & 0.002 \\
& 3 & 0.31 & 1 & 1 & 0.002 & 0.04 & 0.002 \\
\hline $3+5$ & 1 & 1 & 1 & 0.04 & 0.002 & 0.04 & 0.002 \\
& 2 & 1 & 1 & 0.31 & 0.04 & 0.04 & 0.04 \\
& 3 & 1 & 1 & 1 & 0.002 & 0.002 & 0.002 \\
\hline $1+7$ & 1 & 0.04 & 0.31 & 0.31 & 0.04 & 0.31 & 0.04 \\
& 2 & 0.31 & 0.04 & 0.31 & 0.04 & 0.002 & 0.04 \\
& 3 & 0.002 & 1 & 0.002 & 0.04 & 1 & 0.04 \\
\hline $0+8$ & 1 & 0.31 & 0.04 & 0.04 & 0.31 & 1 & 1 \\
& 2 & 0.04 & 0.002 & 1 & 0.31 & 0.04 & 1 \\
& 3 & 0.002 & 0.31 & 0.002 & 0.04 & 0.31 & 0.04 \\
\hline
\end{tabular}

Data is organized by treatment, phase, and state; states are denoted by A, B, C; 6 independent observations 
Table 3: Tobit random effects regressions explaining the Euclidian distance $E D^{1 / n}$ between actual investment and the heuristic $1 / n$

\begin{tabular}{lllll}
\hline Ind. variable & $E D_{T 0+8}^{1 / n}$ & $E D_{T 1+7}^{1 / n}$ & $E D_{T 3+5}^{1 / n}$ & $E D_{T 8+0}^{1 / n}$ \\
\hline Expert dummy & & $26.6^{* * *}(5.8)$ & $41.0^{* * *}(5.0)$ & \\
Client dummy & & $26.4^{* * *}(4.2)$ & $36.2^{* * *}(4.6)$ & \\
Naive dummy & & $16.2^{* * *}(4.1)$ & $32.6^{* * *}(4.7)$ & \\
Phase1*round & $2.4^{* * *}(0.1)$ & $1.4^{* * *}(0.1)$ & $0.5^{* * *}(0.1)$ & $0.2(0.1)$ \\
Phase $2^{*}$ round & $0.7^{* * *}(0.1)$ & $0.4^{* * *}(0.1)$ & $0.0(0.1)$ & $0.0(0.0)$ \\
Phase3*round & $0.6^{* * *}(0.0)$ & $0.3^{* * *}(0.0)$ & $0.2^{* * *}(0.0)$ & $0.2^{* * *}(0.0)$ \\
Constant & $5.8(4.9)$ & & & $31.2^{* * *}(3.1)$ \\
\hline Log likelihood & -9137.6 & -9222.7 & -9017.2 & -8638.5 \\
\hline
\end{tabular}

Tobit regressions by treatment, individual-specific random effects, group-specific fixed effects, 48 individuals, 6 groups, 2,160 observations, standard errors in parentheses,

$$
\text { *** } p<0.01,{ }^{* *} p<0.05,{ }^{*} p<0.1
$$


Table 4: Tobit random effects regressions explaining the Euclidian distance $E D^{w}$ between actual investment and $w$

\begin{tabular}{lllll}
\hline Coefficient & $E D_{0+8}^{w}$ & $E D_{1+7}^{w}$ & $E D_{3+5}^{w}$ & $E D_{8+0}^{w}$ \\
\hline Expert dummy & & $8.8^{*}(5.2)$ & $24.5^{* * *}(6.0)$ & \\
Client dummy & & $19.6^{* * *}(3.8)$ & $27.2^{* * *}(5.6)$ & \\
Naive dummy & & $23.6^{* * *}(3.6)$ & $38.0^{* * *}(5.7)$ & \\
Phase1*period & $1.1^{* * *}(0.1)$ & $0.9^{* * *}(0.1)$ & $0.9^{* * *}(0.1)$ & $1.0^{* * *}(0.1)$ \\
Phase $2^{*}$ period & $0.1^{* *}(0.1)$ & $0.2^{* * *}(0.1)$ & $0.1^{* *}(0.1)$ & $0.2^{* * *}(0.1)$ \\
Phase3*period & $0.2^{* * *}(0.0)$ & $0.2^{* * *}(0.0)$ & $0.2^{* * *}(0.0)$ & $0.2^{* * *}(0.0)$ \\
Constant & $19.0^{* * *}(3.9)$ & & & $15.7^{* *}(6.7)$ \\
\hline Log likelihood & -8894.1 & -8730.2 & -8388.6 & -7396.2 \\
\hline
\end{tabular}

Tobit regressions by treatment, individual-specific random effects, group-specific fixed effects, 48 individuals, 6 groups, 2,160 observations, standard errors in parentheses,

$$
{ }^{* * *} p<0.01,{ }^{* *} p<0.05,{ }^{*} p<0.1
$$


Table 5: Supply and demand on the market for professional expertise by treatment and phase

\begin{tabular}{ccrrrr}
\hline \multirow{2}{*}{$\begin{array}{c}\text { Treat- } \\
\text { ment }\end{array}$} & Phase & \multicolumn{2}{c}{ Share of nonexperts who... } & \multicolumn{2}{c}{ Share of experts who... } \\
\cline { 3 - 6 } & & ...ask for advice & ...receive advice & ...are willing to advise & ...become advisors \\
\hline \multirow{3}{*}{$3+5$} & 2 & $28 / 30(93 \%)$ & $15 / 28(54 \%)$ & $15 / 18(83 \%)$ & $7 / 15(47 \%)$ \\
& 3 & $26 / 30(87 \%)$ & $23 / 26(88 \%)$ & $15 / 18(83 \%)$ & $7 / 15(47 \%)$ \\
& all & $82 / 90(91 \%)$ & $57 / 82(70 \%)$ & $43 / 54(80 \%)$ & $22 / 43(51 \%)$ \\
\hline \multirow{2}{*}{$1+7$} & 1 & $39 / 42(93 \%)$ & $10 / 39(26 \%)$ & $5 / 6(83 \%)$ & $5 / 5(100 \%)$ \\
& 2 & $41 / 42(98 \%)$ & $19 / 41(46 \%)$ & $6 / 6(100 \%)$ & $6 / 6(100 \%)$ \\
& 3 & $40 / 42(95 \%)$ & $7 / 40(18 \%)$ & $4 / 6(67 \%)$ & $2 / 4(50 \%)$ \\
& all & $120 / 126(95 \%)$ & $36 / 120(30 \%)$ & $15 / 18(83 \%)$ & $13 / 15(87 \%)$ \\
\hline
\end{tabular}


Table 6: Mean, median, and standard deviation of investment of clients as well as advice they receive

\begin{tabular}{ccccccccccc}
\hline \multirow{2}{*}{$\begin{array}{c}\text { Treat } \\
\text { ment }\end{array}$} & Pha & \multicolumn{3}{c}{ Mean } & \multicolumn{4}{c}{ Median } & \multicolumn{3}{c}{ SD } \\
& se & A & B & C & A & B & C & A & B & C \\
\hline \multirow{3}{*}{ 3+5 Investment } & 1 & 22 & 21 & 58 & 20 & 20 & 60 & 15 & 15 & 27 \\
& 2 & 42 & 18 & 40 & 40 & 15 & 40 & 17 & 16 & 17 \\
& 3 & 19 & 29 & 52 & 15 & 30 & 55 & 18 & 15 & 25 \\
\hline \multirow{3}{*}{ 3+5 Advice } & 1 & 20 & 19 & 61 & 20 & 20 & 60 & 14 & 12 & 24 \\
& 2 & 43 & 16 & 41 & 40 & 20 & 40 & 7 & 9 & 7 \\
& 3 & 11 & 28 & 61 & 10 & 30 & 60 & 8 & 9 & 10 \\
\hline \multirow{3}{*}{ 1+7 Investment } & 1 & 25 & 24 & 51 & 25 & 25 & 50 & 11 & 18 & 22 \\
& 2 & 40 & 20 & 40 & 40 & 15 & 40 & 20 & 22 & 21 \\
& 3 & 14 & 31 & 54 & 10 & 30 & 50 & 15 & 17 & 23 \\
\hline \multirow{3}{*}{ 1+7 Advice } & 1 & 21 & 21 & 58 & 20 & 20 & 60 & 7 & 9 & 13 \\
& 2 & 43 & 13 & 44 & 40 & 10 & 45 & 13 & 9 & 11 \\
& 3 & 8 & 28 & 64 & 10 & 30 & 65 & 5 & 13 & 14 \\
\hline
\end{tabular}

Data is organized by treatment, phase, and state; benchmark:

$w_{1}=(25,25,50), w_{2}=(40,20,40), w_{3}=(15,30,55), 1 / n$ heuristic $=(100 / 3,100 / 3,100 / 3) ;$ states are denoted by A, B, C 
Table 7: Wilcoxon rank-sum test $p$ values for equality between investment of clients and recommendations

\begin{tabular}{cccccc}
\hline Treatment & Phase & \multicolumn{2}{c}{$\begin{array}{c}\text { Number of ind. } \\
\text { observations }\end{array}$} & \multicolumn{4}{c}{$p$ value } \\
& & 6 & 0.75 & 0.75 & 0.87 \\
\hline \multirow{2}{*}{ T 3+5 } & 2 & 5 & 0.92 & 0.92 & 0.46 \\
& 3 & 6 & 0.08 & 0.87 & 0.11 \\
\hline \multirow{2}{*}{ T 1+7 } & 1 & 5 & 0.25 & 0.46 & 0.35 \\
& 2 & 6 & 0.34 & 0.15 & 0.42 \\
& 3 & 2 & 0.12 & 1 & 0.43 \\
\hline
\end{tabular}

Data is organized by treatment, phase, and state; states are denoted by A, B, C 
Table 8: Tobit random effects regressions explaining profits by treatment

\begin{tabular}{lcccc}
\hline Coefficient & Profit T 8+0 & Profit T 3+5 & Profit T 1+7 & Profit T 0+8 \\
\hline$E D_{w}$ & $-0.24^{* * *}(0.1)$ & $-0.28(0.1)^{* * *}$ & $-0.72^{* * *}(0.1)$ & $-0.61^{* * *}(0.1)$ \\
$E D_{1 / n}$ & $-0.09(0.1)$ & $-0.11(0.1)$ & $0.15^{* *}(0.1)$ & $0.08(0.1)$ \\
Round & $0.01(0.1)$ & $0.03(0.1)$ & $0.06(0.1)$ & $0.01(0.1)$ \\
Const & $108.22^{* * *}(3.6)$ & $109.94^{* * *}(5.1)$ & $113.44^{* * *}(4.6)$ & $112.71^{* * *}(4.4)$ \\
\hline
\end{tabular}

Log likelihood $\quad-11010.4 \quad-11338.1 \quad-11317.8 \quad-11099.5$

Tobit regressions by treatment, individual-specific random effects, group-specific fixed effects, 48 individuals, 6 groups, 2,160 observations, standard errors in parentheses, *** $p<0.01, * * p<0.05, * p<0.1, \mathrm{ED}=$ Euclidian distance 
Figure 1: Mean required fees, mean willingness to pay, and mean paid fees

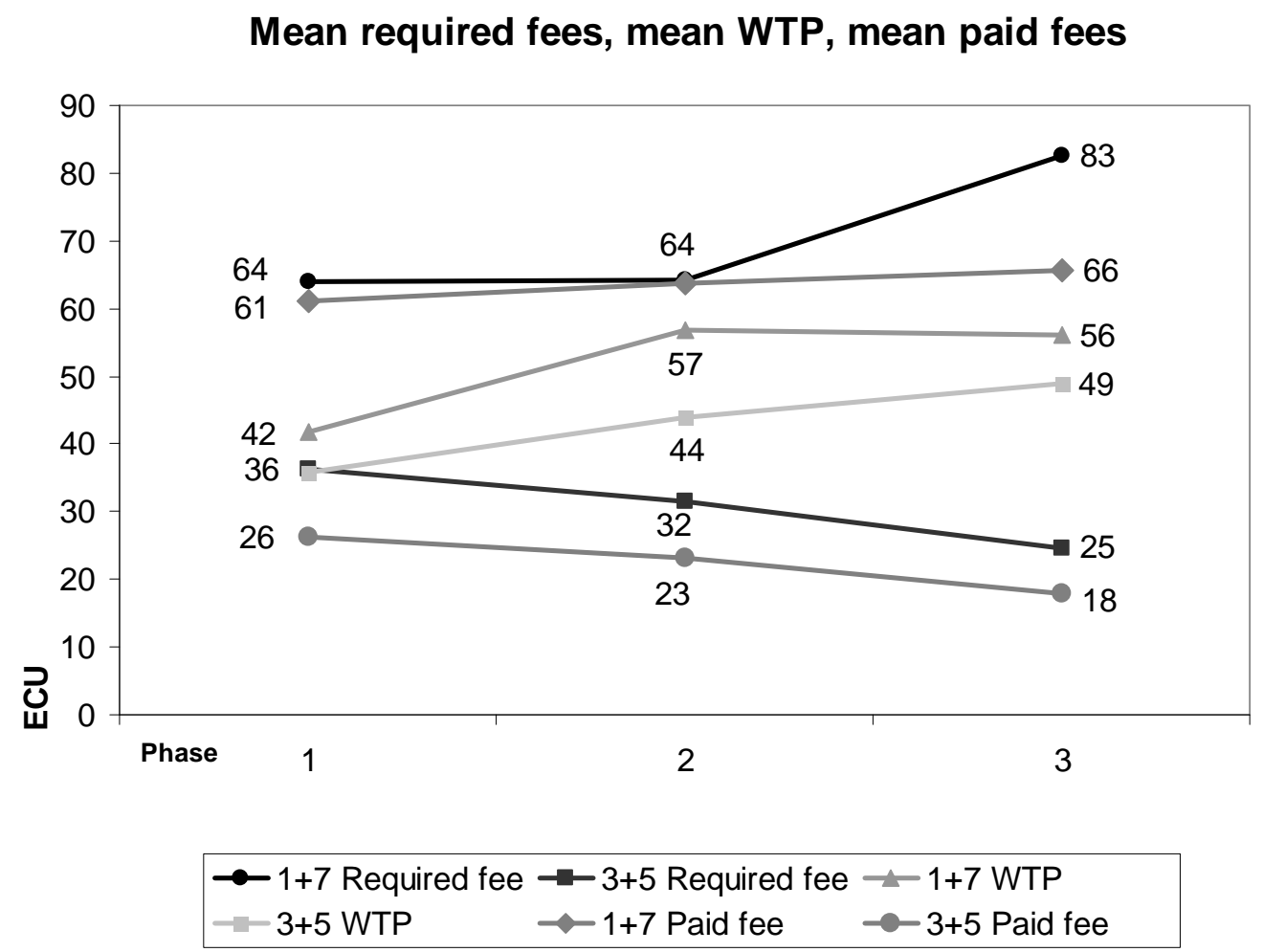




\section{References}

Alós-Ferrer, C., Ania, A. B., 2005. The asset market game. Journal of Mathematical Economics 41, 67-90.

Ball, C. T., Langholtz, H. J., Auble, J., Sopchak, B., 1998. Resource-allocation strategies: A verbal protocol analysis. Organizational Behavior \& Human Decision Processes 76, 70-88.

Benartzi, S., Thaler, R. H., 2001. Naive diversification strategies in defined contribution saving plans. American Economic Review 91, 79-98.

Blume, L., Easley, D., 1992. Evolution and market behavior. Journal of Economic Theory 58, 9-40.

Bonaccio, S., Dalal, R. S., 2006. Advice taking and decision-making: An integrative literature review, and implications for the organizational sciences. Organizational Behavior \& Human Decision Processes 101, 127-151.

Busemeyer, J. R., Swenson, K., Lazarte, A., 1986. An adaptive approach to resource allocation. Organizational Behavior \& Human Decision Processes 38, 318-341.

Cameron, C., Trivedi, P. K., 2005. Microeconometrics: Methods and Applications. Cambridge: Cambridge University Press.

Chaudhuri, A., Graziano, S., Maitra, P., 2006. Social learning and norms in a public goods experiment with inter-generational advice. Review of Economic Studies 73, $357-380$.

Crawford, V. P., Sobel, J., 1982. Strategic information transmission. Econometrica $50,1431-1451$. 
Farrell, J., Rabin, M., 1996. Cheap talk. Journal of Economic Perspectives 10, $103-118$.

Fischbacher, U., 2007. z-Tree: Zurich toolbox for ready-made economic experiments. Experimental Economics 10, 171-178.

Gehrig, T., Güth, W., Levinsky, R., Popova, V., 2008. Do investors optimize, follow heuristics, or listen to experts? Jena Economic Research Papers 2008-086.

Gibbons, A. M., Sniezek, J. A., Dalal, R. S., 2003. Antecedents and consequences of unsolicited versus explicitly solicited advice. In: Budescu, D. (Chair). Symposium in Honor of Janet Sniezek. Symposium presented at the annual meeting of the Society for Judgement and Decision Making, Vancouver, BC.

Gigerenzer, G., Todd, P. M., 1999. Simple Heuristics That Make Us Smart. Oxford: Oxford University Press.

Greiner, B., 2004. An online recruitment system for economic experiments. In: Kremer, K., Macho, V. (Eds.). Forschung und wissenschaftliches Rechnen 2003. Gesellschaft fuer Wissenschaftliche Datenverarbeitung Bericht 63, Goettingen, $79-93$

Harvey, N., Fischer, I., 1997. Taking advice: Accepting help, improving judgement, and sharing responsibility. Organizational Behavior \& Human Decision Processes $70,117-133$.

Harvey, N., Harries, C., 2004. Effects of judges' forecasting on their later combination of forecasts for the same outcomes. International Journal of Forecasting 20, $391-409$.

Iyengar, R., Schotter, A., 2008. Learning under supervision: An experimental study. Experimental Economics 11, 154-173. 
Krishna, V., Morgan, J., 2008. Cheap Talk. In: Durlauf, S. N., Blume, L. E. (Eds.). The New Palgrave Dictionary of Economics, 2nd ed., Vol. 1. New York: McMillan, $751-756$.

Krueger, J. L., 2003. Return of the ego - self-referent information as a filter for social prediction: Comment on Karniol (2003). Psychological Review 110, 585-590.

Kuang, X., Weber, R., Dana, J., 2007. How effective is advice from interested parties? An experimental test using a pure coordination game. Journal of Economic Behavior and Organization 62, 591-604.

Langholtz, H., Gettys, C., Foote, B., 1993. Resource-allocation behavior under certainty, risk, and uncertainty. Organizational Behavior \& Human Decision Processes 54, 203-224.

Langholtz, H., Gettys, C., Foote, B., 1994. Allocating resources over time in benign and harsh environments. Organizational Behavior \& Human Decision Processes $58,28-50$.

Langholtz, H. J., Ball, C., Sopchak, B., Auble, J., 1997. Resource-allocation behavior in complex but commonplace tasks. Organizational Behavior \& Human Decision Processes 70, 249-266.

Nash, J., 1951. Non-cooperative games. The Annals of Mathematics 54, 286-295.

Rieskamp, J., Busemeyer, J. R., Laine, T., 2003. How do people learn to allocate resources? Comparing two learning theories. Journal of Experimental Psychology: Learning, Memory, \& Cognition 29, 1066-1081.

Schotter, A., 2003. Decision making with naive advice. American Economic Review 93, 196-201. 
Schotter, A., Sopher, B., 2003. Social learning and coordination conventions in intergenerational games: An experimental study. Journal of Political Economy $111,498-529$.

Schotter, A., Sopher, B., 2006. Trust and trustworthiness in games: An experimental study of intergenerational advice. Experimental Economics 9, 123-145.

Schotter, A., Sopher, B., 2007. Advice and behavior in intergenerational ultimatum games: An experimental approach. Games and Economic Behavior 58, 365-393.

Schrah, G. E., Dalal, R. S., Sniezek, J., 2006. The adaptive decision-maker is not an island: Integrating expert advice with information search. Journal of Behavioral Decision Making 19, 43-60.

Sobel, J., 2007. Signalling Games. In: Sotomayor, M. (Ed.). Encyclopedia of Complexity and System Science. Springer, forthcoming.

Tversky, A., Kahnemann, D., 1974. Judgement under uncertainty: Heuristics and biases. Science 185, 1124-1131.

Vulkan, N., 2000. An economist's perspective on probability matching. Journal of Economic Surveys 14, 101-118.

Yaniv, I. (2004a). The benefit of additional opinions. Current Directions in Psychological Science 13, 75-78.

Yaniv, I., 2004b. Receiving other people's advice: Influence and benefit. Organizational Behavior \& Human Decision Processes 93, 1-13.

Yaniv, I., Kleinberger, E., 2000. Advice taking in decision making: Egocentric discounting and reputation formation. Organizational Behavior \& Human Decision Processes 83, 260-281. 


\section{Appendix}

\section{Proof of Proposition 1}

Let us recall that agent $i \in N$ is distributing amount $K_{i}$ between $S$-states. Formally, she invests shares $e_{i}=\left(e_{i 1}, \ldots, e_{i S}\right)$ in states that are realized with probabilities $w=\left(w_{1}, \ldots w_{S}\right)$.

Normalize $K=\sum_{i=1}^{N} K_{i}=1$ and denote the total amount invested in state $s$ by $p_{s}$, i.e.

$$
p_{s}=\sum_{i=1}^{N} e_{i s} K_{i} \text { for } s=1, \ldots, S .
$$

Choosing $e_{i}=\left(e_{i 1}, \ldots, e_{i S}\right)$, agent $i$ earns in expected terms

$$
\pi_{i}=\sum_{s=1}^{S} w_{s} \frac{e_{i s} K_{i}}{p_{s}} \text { for } i=1, \ldots, N
$$

Since for each agents the sum of shares equals to 1 , each agent $i$ maximizes

$$
\mathcal{L}=\pi_{i}+\lambda_{i}\left(1-e_{i 1}-\ldots-e_{i S}\right)
$$

Since $\partial p_{s} / \partial e_{i s}=1$, we obtain first order condition

$$
\frac{\partial \mathcal{L}}{\partial e_{i s}}=\frac{w_{s} K_{i}}{p_{s}}-\frac{w_{s} e_{i s} K_{i}}{p_{s}^{2}}-\lambda_{i}=0 \text { for } s=1, \ldots, S .
$$

This requires for an interior equilibrium that for any two states $s, r \in\{1, \ldots, S\}$

$$
\frac{w_{s}}{p_{s}}\left(1-\frac{e_{i s}}{p_{s}}\right)=\frac{w_{r}}{p_{r}}\left(1-\frac{e_{i r}}{p_{r}}\right) .
$$

Suppose now there exists an equilibrium allocation with

$$
\frac{w_{s}}{p_{s}} \neq \frac{w_{r}}{p_{r}}
$$

for some states $s$ and $r$. Of course, without loss of generality we can assume, e.g., $\frac{w_{s}}{p_{s}}<\frac{w_{r}}{p_{r}}$. Then, from (4), we get

$$
\left(1-\frac{e_{i s}}{p_{s}}\right)>\left(1-\frac{e_{i r}}{p_{r}}\right) \Rightarrow \frac{e_{i s}}{p_{s}}<\frac{e_{i r}}{p_{r}} \Rightarrow \frac{e_{i s} K_{i}}{p_{s}}<\frac{e_{i r} K_{i}}{p_{r}} \quad \forall i \in\{1, \ldots, N\} .
$$


Summing (5) for all $i$, we get

$$
\frac{\sum_{i=1}^{N} e_{i s} K_{i}}{p_{s}}<\frac{\sum_{i=1}^{N} e_{i r} K_{i}}{p_{r}},
$$

and, consequently, an invalid statement $1<1$. Therefore, only allocations with $\frac{w_{s}}{p_{s}}=\frac{w_{r}}{p_{r}}$ can satisfy (4).

Assuming $w_{s} \neq 0 \forall s$ we can divide (4) by $\frac{w_{s}}{p_{s}}$ to get

$$
\frac{e_{i s}}{p_{s}}=\frac{e_{i r}}{p_{r}} \quad \forall i \in\{1, \ldots, N\}
$$

We conclude that only allocations with

$$
\frac{w_{s}}{p_{s}}=\frac{w_{r}}{p_{r}} \quad \text { and } \quad \frac{e_{i s}}{p_{s}}=\frac{e_{i r}}{p_{r}}
$$

satisfy the equilibrium condition (4). However, condition (6) corresponds to

$$
\frac{w_{s}}{w_{r}}=\frac{p_{s}}{p_{r}}=\frac{e_{i s}}{e_{i r}}
$$

and uniquely defines the equilibrium that corresponds to the evolutionarily stable allocation $e_{i}=e^{*}=w$ for all $i=1, \ldots, N$ of Blume and Easley (1992). 


\section{Figures}

Figure 2: Euclidian distance from the $1 / n$ portfolio by treatment over time
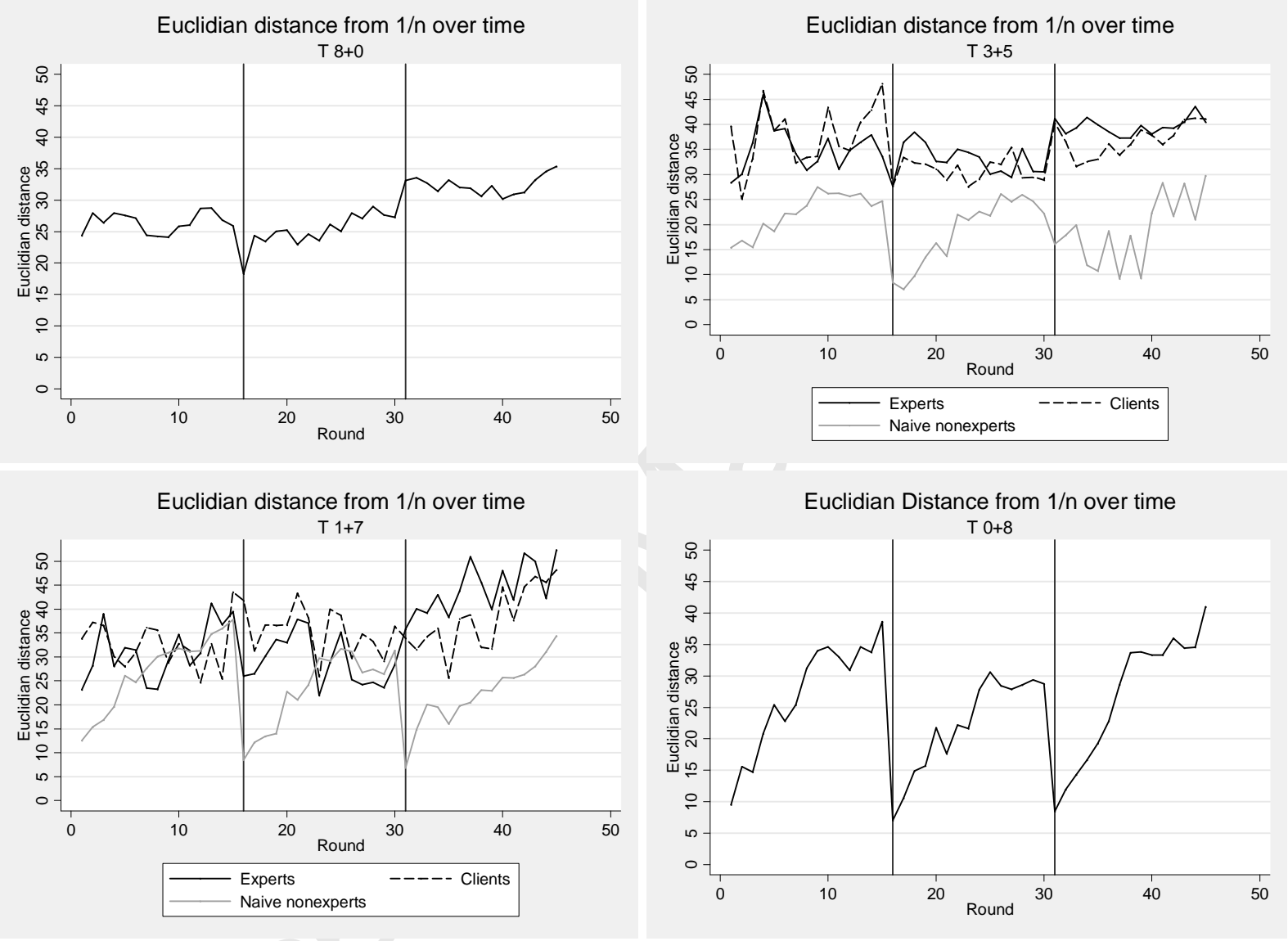
Figure 3: Euclidian distance from the $w$-portfolio by treatment over time
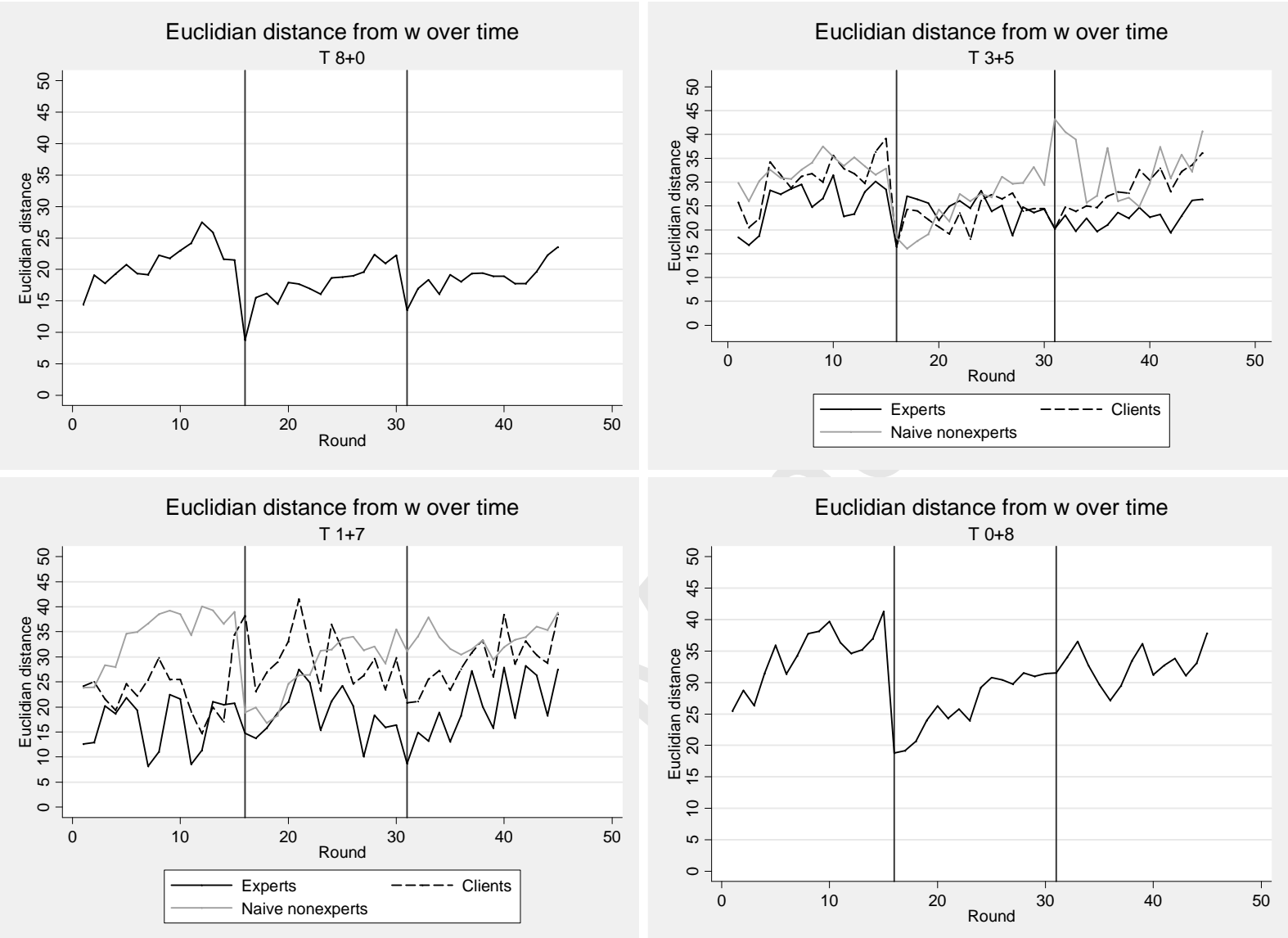
Figure 4: Euclidian distance from the recommended portfolio by treatment over time
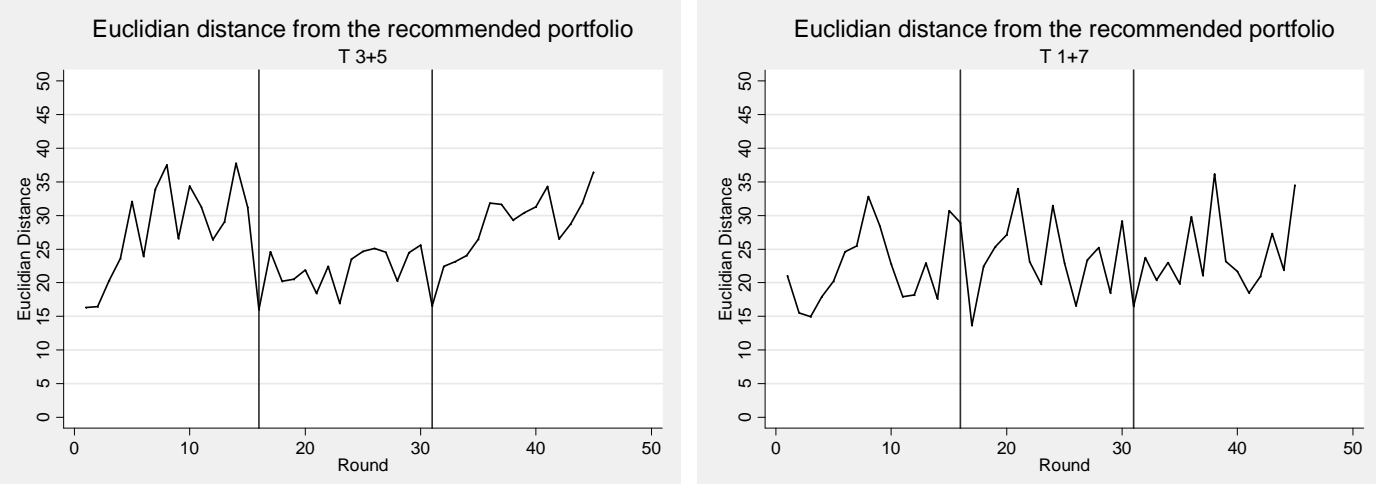